\title{
Origins of tropical-wide SST biases in CMIP multi-model ensembles
}

\author{
Gen $\mathrm{Li}^{1,2,3}$ and Shang-Ping $\mathrm{Xie}^{2,3,4}$ \\ Received 3 September 2012; revised 20 October 2012; accepted 23 October 2012; published 29 November 2012.
}

[1] Long-standing simulation errors limit the utility of climate models. Overlooked are tropical-wide errors, with sea surface temperature (SST) biasing high or low across all the tropical ocean basins. Our analysis based on Coupled Model Intercomparison Project (CMIP) multi-model ensembles shows that such SST biases can be classified into two types: one with a broad meridional structure and of the same sign across all basins that is highly correlated with the tropical mean; and one with large inter-model variability in the cold tongues of the equatorial Pacific and Atlantic. The first type can be traced back to biases in atmospheric simulations of cloud cover, with cloudy models biasing low in tropical-wide SST. The second type originates from the diversity among models in representing the thermocline depth; models with a deep thermocline feature a warm cold tongue on the equator. Implications for inter-model variability in precipitation climatology and SST threshold for convection are discussed. Citation: Li, G., and S.-P. Xie (2012), Origins of tropical-wide SST biases in CMIP multi-model ensembles, Geophys. Res. Lett., 39, L22703, doi:10.1029/2012GL053777.

\section{Introduction}

[2] State-of-the-art coupled ocean-atmosphere general circulation models (CGCMs) suffer from large errors in simulating tropical climate, limiting their utility in climate prediction and projection. Sea surface temperature (SST) errors are comparable or larger in magnitude than observed interannual variability and projected change in the 21 st century. Well-known errors include too weak a zonal SST gradient along the equatorial Atlantic [Davey et al., 2002; Richter and Xie, 2008]; an equatorial cold tongue that penetrates too far westward in the Pacific [Mechoso et al., 1995; de Szoeke and Xie, 2008]; too warm SSTs over the tropical Southeast Pacific and Atlantic, and a spurious double intertropical convergence zone [Lin, 2007]. Since ocean and atmosphere are closely coupled in the tropics, the development of these errors involves positive feedback [Cai et al., 2011], e.g., Bjerknes feedback for cold tongue biases and wind-evaporation-SST (WES) feedback for the double ITCZ syndrome. These errors have persisted in several generations of models for more than a decade. Identifying the sources and

\footnotetext{
${ }^{1}$ School of Earth and Space Sciences, University of Science and Technology of China, Hefei, China.

${ }^{2}$ International Pacific Research Center, SOEST, University of Hawaii at Manoa, Honolulu, Hawaii, USA.

${ }^{3}$ Scripps Institution of Oceanography, La Jolla, California, USA.

${ }^{4}$ Physical Oceanography Laboratory, Ocean University of China, Qingdao, China.
}

Corresponding author: G. Li, International Pacific Research Center, SOEST, University of Hawaii at Manoa, Honolulu, HI 96822, USA. (ligen@hawaii.edu)

C 2012. American Geophysical Union. All Rights Reserved. 0094-8276/12/2012GL053777 reducing these errors are an important topic in the climate research and modeling communities.

[3] Previous studies focus almost exclusively on model errors in representing spatial patterns, e.g., the east-west contrast across the equatorial Pacific and Atlantic, and meridional gradient across the equator that controls the ITCZ position. Close inspection of zonal SST profiles along the equator reveals basin-wide offsets, most obvious in the Indian [Saji et al., 2006, Figure 8a] but visible in the Pacific [de Szoeke and Xie, 2008, Figure 7c], and Atlantic [Richter and Xie, 2008, Figure 2] Oceans. It is unclear whether such basin-wide offset errors are limited to individual tropical basins or shared among all the basins. There are physical reasons for developing tropical-wide offset errors. For example, tropospheric temperature is nearly uniform in space within the tropics, flattened by fast communications by equatorial waves [Sobel et al., 2002].

[4] The present study investigates the nature and sources of such offset errors in tropical SST in the Coupled Model Intercomparison Projection (CMIP) phase 3 and 5 multi-model ensembles. We show that the offset errors are tropical wide and can be classified into two types. The first type is associated with the tropical mean SST differences from observations and among models, and the second type is reflected in the cold tongue temperatures in the equatorial Pacific and Atlantic. Our analysis shows that the first-type offset error is due to atmospheric model representation of cloud cover, and the second type is of oceanic origin. Our study highlights the tropical-wide offset errors and is an important step toward reducing them in future model development/improvement efforts. The tropical mean SST, for example, is important in setting the threshold for tropical deep convection. The convective threshold and tropical mean SST are about $26.5-27.0^{\circ} \mathrm{C}$ in current climate but vary a great deal among CMIP3 models and the inter-model variability is highly correlated [Johnson and Xie, 2010]. Our study takes a step forward to address the important question of what gives rise to inter-model variability in the tropical mean SST and hence the convective threshold.

[5] The rest of the paper is organized as follows. Section 2 describes models used in this study. Sections 3 and 4 introduce tropical-wide model biases and investigate their sources, respectively. Section 5 is a summary with discussion.

\section{Models}

[6] We examine the Climate of the Twentieth Century (20C3M) simulations (also termed as "historical" runs) from 22 CMIP3 and 21 CMIP5 CGCMs for a 30-yr period of 1970-99, together with their available Atmospheric Model Intercomparison Project (AMIP) runs that are forced with the observed SST. Table S1 of the auxiliary material lists these models. ${ }^{1}$ The description of individual models can be obtained at http://www-pcmdi.llnl.gov/ [Meehl et al., 2007;

\footnotetext{
${ }^{1}$ Auxiliary materials are available in the HTML. doi:10.1029/ 2012GL053777.
} 

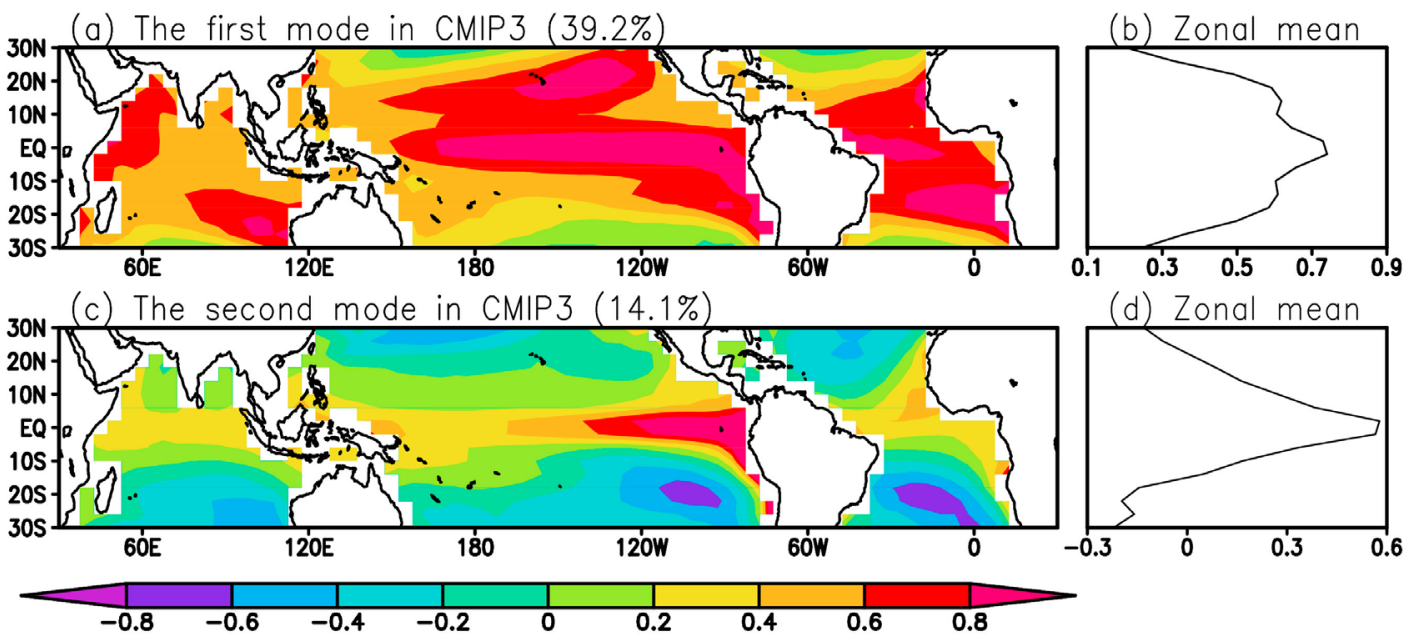

(e)

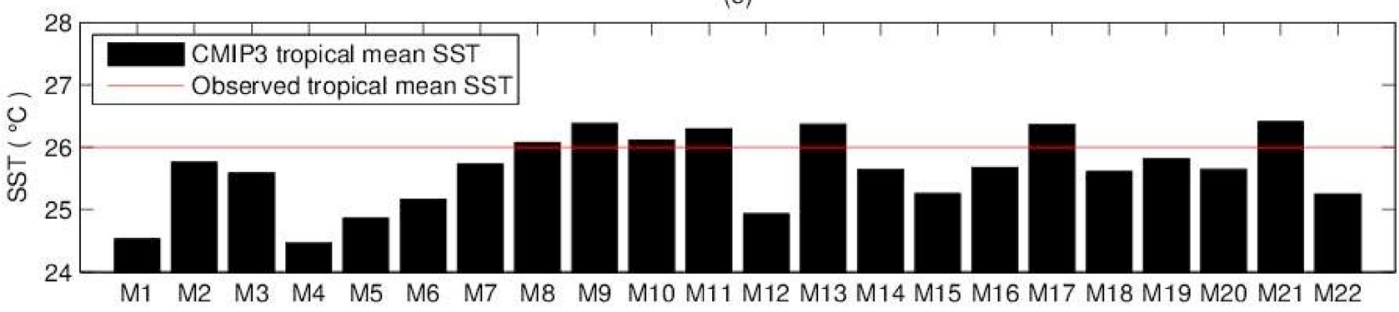

(f)

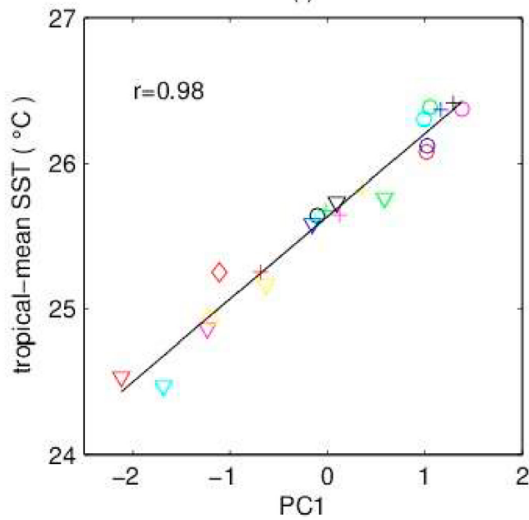

(g)

\begin{tabular}{|cl|rr|}
\hline$\nabla$ & $M 1$ & & $M 12$ \\
$\nabla$ & M2 & 0 & $M 13$ \\
$\nabla$ & $M 3$ & 0 & $M 14$ \\
$\nabla$ & $M 4$ & + & $M 15$ \\
$\nabla$ & $M 5$ & + & $M 16$ \\
& M6 & + & $M 17$ \\
$\nabla$ & $M 7$ & + & $M 18$ \\
0 & $M 8$ & & $M 19$ \\
0 & $M 9$ & + & $M 20$ \\
0 & $M 10$ & + & $M 21$ \\
0 & $M 11$ & $\diamond$ & $M 22$ \\
\hline
\end{tabular}

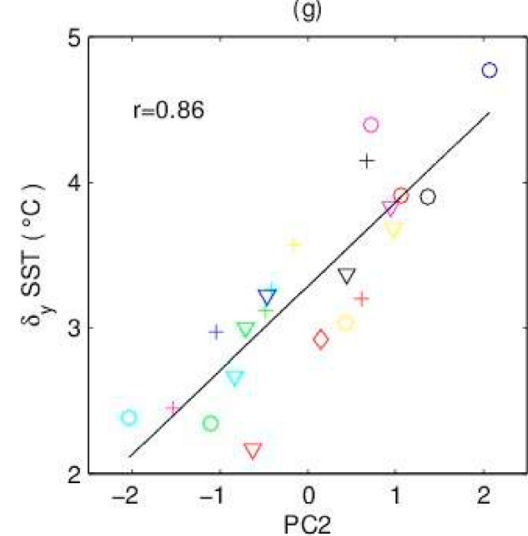

Figure 1. (a) First and (c) second inter-model EOF patterns of annual mean SST climatology over tropical oceans in 22 CMIP3 models, along with the (b and d) zonal mean. (e) Tropical mean SST $\left({ }^{\circ} \mathrm{C}\right)$ in CMIP3 models and HadISST observation (red line). Relationship between (f) PC1 and tropical mean SST in CMIP3 models, and (g) PC2 and SST difference between the equatorial $\left(5^{\circ} \mathrm{S}-5^{\circ} \mathrm{N}\right)$ and subtropical $\left(15^{\circ} \mathrm{S} / \mathrm{N}-30^{\circ} \mathrm{S} / \mathrm{N}\right)$ oceans. The numbers at the top of Figures $1 \mathrm{a}$ and $1 \mathrm{c}$ indicate the explained variance.

Taylor et al., 2012]. For each model, we use monthly mean SST, downward/upward shortwave (SW)/longwave (LW) radiation, latent heat flux (LHF), and sensible heat flux (SHF) at the sea surface; surface winds; precipitation; total cloud fraction (TCF); ocean temperature, and current velocity. Because we are interested only in large-scale features, unless otherwise specified, all model outputs are interpolated to a $5^{\circ} \times 4^{\circ}$ grid.

\section{Inter-model Diversity}

[7] Figure 1e shows the annual mean SST averaged over tropical oceans $\left(30^{\circ} \mathrm{S}-30^{\circ} \mathrm{N}\right)$ simulated in 22 CMIP3 models and HadISST observations. Consistent with a previous study
[Lin, 2007], tropical mean SST is biased low in most CGCMs, with considerable inter-model spread of up to $2{ }^{\circ} \mathrm{C}$. We examine the inter-model variability of annual mean SST climatology over tropical oceans by performing an intermodel Empirical Orthogonal Function (EOF) analysis for 22 CMIP3 CGCMs. The first inter-model EOF mode (EOF1), explaining $39.2 \%$ of total variance, exhibits a broad pattern of the same sign over the entire tropics, with a maximum on the equator (Figures $1 \mathrm{a}$ and $1 \mathrm{~b}$ ). The first principal component (PC1) is highly correlated with tropical mean SST at 0.98 (Figure 1f). We choose three models of highest PC1 values as the warm tropics (wT) models (M13, M17, and M21), and three of lowest PC1 values as the cool tropics (cT) models (M1, M4, and M5). 

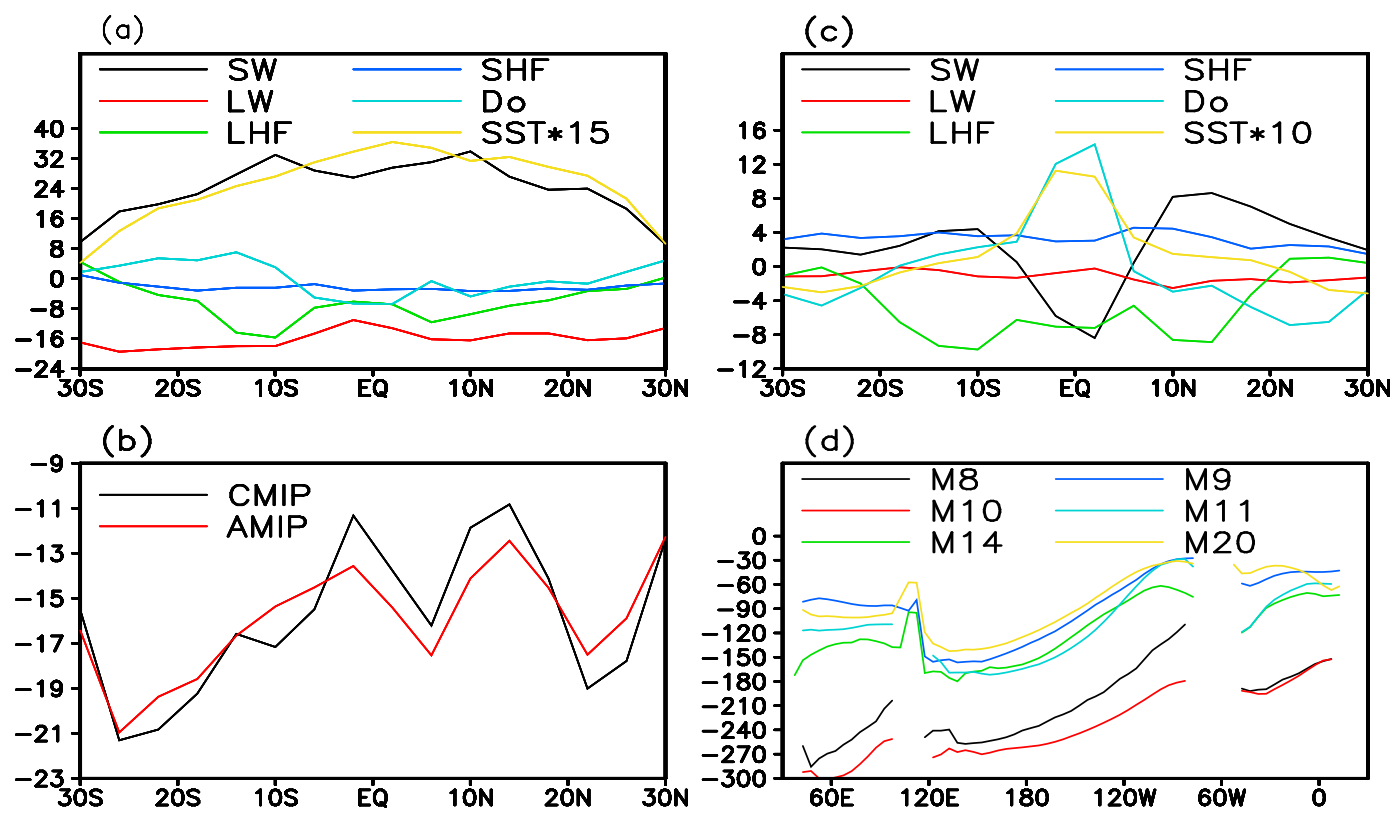

Figure 2. Meridional profiles of wT minus cT composite difference of (a) SST $\left({ }^{\circ} \mathrm{C}\right)$ and terms $\left(\mathrm{W} / \mathrm{m}^{2}\right)$ in equation $(1)$, and (b) TCF (\%) in CMIP and AMIP runs. (c) Same as in (a) but between wCT and cCT models. (d) Zonal profiles of Z20 (m) at the equator in $\mathrm{WCT}$ and $\mathrm{cCT}$ models.

[8] The second inter-model EOF mode (EOF2), explaining $14.1 \%$ of total variance, features a sharp peak on the equator, especially in the Pacific cold tongue, and weak SST anomalies of opposite sign in the subtropics (Figures 1c and 1d). The PC2 has a high correlation at 0.86 with the SST differences between the equatorial and subtropical oceans (Figure 1g). We choose three models of highest PC2 values as the warm cold tongue (wCT) models (M8, M10, and M14), and three of lowest PC2 values as the cool cold tongue (cCT) models (M9, M11, and M20).

[9] The inter-model EOF analysis is also applied to intermodel variability in annual mean SST over the tropics in 22 CMIP3 and 21 CMIP5 CGCMs. The two leading EOF patterns (Figure S1 of the auxiliary material) are very similar to those of CMIP3. The next section examines the sources of inter-model diversity based on CMIP3.

\section{Sources of Biases}

\subsection{EOF1}

[10] For climatology, the mixed-layer heat budget can be expressed as follows [Xie et al., 2010]:

$$
Q_{\mathrm{SW}}+Q_{\mathrm{LW}}+Q_{\mathrm{LHF}}+Q_{\mathrm{SHF}}+D o=0,
$$

where $Q_{\mathrm{SW}}, Q_{\mathrm{LW}}, Q_{\mathrm{LHF}}$, and $Q_{\mathrm{SHF}}$ denote net SW, net LW, LHF, and SHF (positive downward), respectively; and Do is the ocean heat transport effect due to three-dimensional advection and mixing. The inter-model diversity of surface heat fluxes and Do could contribute to that of SST. Figure 2a shows the inter-model diversity of tropical SST climatology among CGCMs identified in EOF1 based on the zonal-mean differences of SST and various terms in equation (1) between wT and cT models. Indeed, wT models have warmer SSTs consistently at all latitudes than cT ones, associated with more SW into the ocean, and more LW and LHF away from the ocean. The differences of SHF and Do between wT and
cT models are small. This suggests that the inter-model diversity in tropical mean SST as represented by EOF1 is primarily caused by that of SW. The more (less) SW into the ocean in wT (cT) models warms (cools) the SST; and the warmer (colder) SST induces more (less) LW and LHF from the ocean to balance SW anomalies.

[11] The inter-model spread of SW arises from that of cloud amount. Figure $2 \mathrm{~b}$ compares the meridional profiles of TCF difference between wT and cT models in both CMIP and AMIP runs. Indeed, wT models have less TCF at all latitudes of the analysis domain than cT ones. Moreover, the TCF difference between coupled wT and cT models can be traced back to that in AMIP simulations. Although the cloud type is not included in the CMIP output, that the TCF difference is large in the subtropics hints that low cloud contributes most, consistent with a previous study [Bony and Dufresne, 2005]. Note that Figure $2 \mathrm{~b}$ is calculated from M4, M13, and M17 since only a subset of AMIP simulations is available for analysis. This does not affect the result significantly because the composite TCF difference between coupled wT and cT models shown here is very similar if more CMIP models are selected.

[12] In short, the atmospheric component of wT (cT) models produces less (more) cloud, and the excess (deficient) SW causes higher (lower) SST in CGCMs. Thus, the inter-model diversity identified in EOF1 results from that of the atmospheric component of CGCMs in simulating cloud. This explains the source of such offset error in tropical SST among the CGCMs. An analysis similar to Figure 2a but with observations as the reference shows that the CMIP ensemble mean cold SST bias (Figure 1e) is linked to the models' underestimation of SW (Figure S2 of the auxiliary material), which is in turn due to cloud-radiative forcing.

\subsection{EOF2}

[13] Figure 2c shows the zonal-mean differences of SST and various terms in equation (1) between ${ }^{\mathrm{wCT}}$ and $\mathrm{cCT}$ 

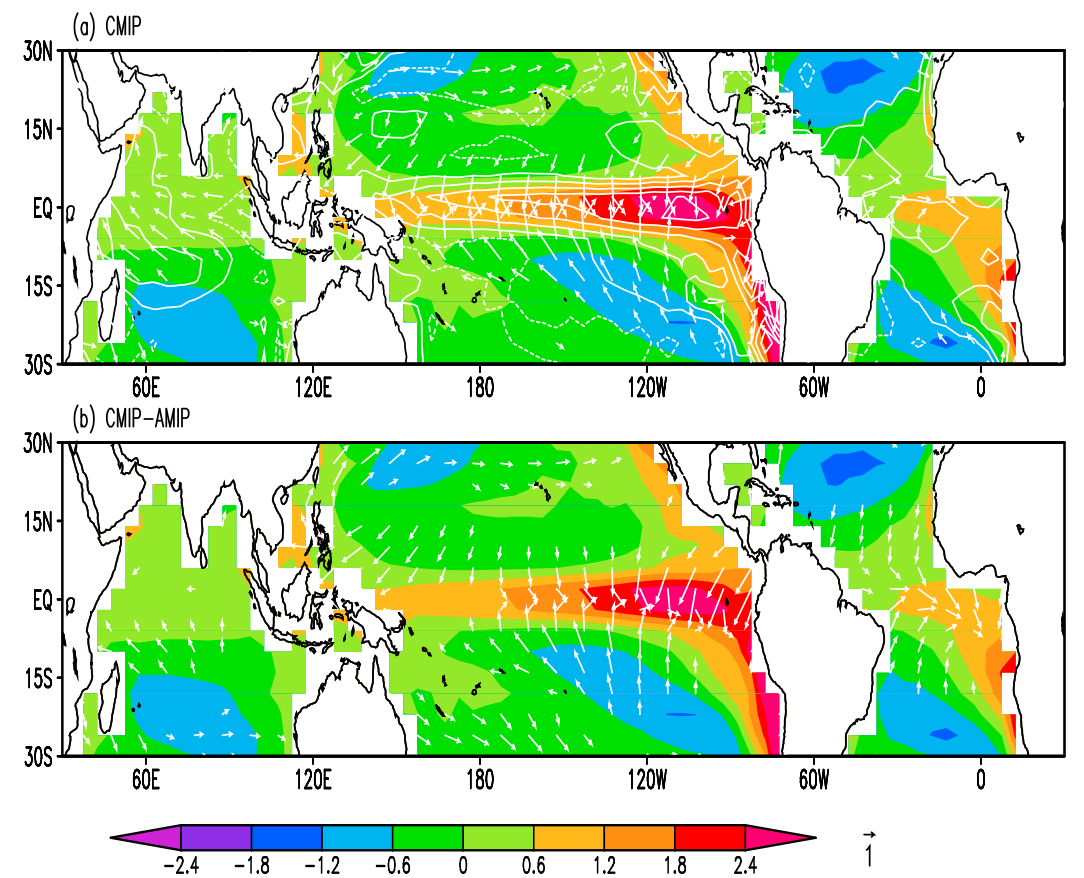

Figure 3. wCT minus cCT composite difference of SST (color shaded, ${ }^{\circ} \mathrm{C}$ ), surface wind velocity (m/s; wind speed smaller than $0.5 \mathrm{~m} / \mathrm{s}$ has been masked out), and $D_{O}$ (contour interval: $10 \mathrm{~W} / \mathrm{m}^{2}$ ) in (a) CMIP, and (b) CMIP-AMIP.

models. wCT models have warmer SST at the equator than cCT models, and the main contributor to warm SST on the equator is the term Do, which is balanced by LHF and SW. Thus, the increased $D o$ at the equator in wCT models warms SST. Warmer SST induces more LHF and cloud, reducing SW into the ocean. The surface flux adjustments balance the Do change.

[14] In the equatorial Pacific cold tongue where the mean thermocline is shallow, ocean upwelling plays a key role in controlling SST and its variability [Wang and Picaut, 2004; Chang et al., 2006]. Figure 2d shows the annual mean distribution of thermocline depth (represented by the $20^{\circ} \mathrm{C}$ isotherm depth, Z20 hereafter) along the equator in wCT and cCT models. WCT models have a deeper thermocline than cCT models along the equator in all three basins. Indeed, models with a greater (smaller) PC2 tend to have a deeper (shallower) thermocline depth averaged along the equator, and the inter-model relationship between them is statistically significant (Figure S3 of the auxiliary material). Also, weaker (stronger) upwelling occurs in the equatorial eastern Pacific in wCT (cCT) models with a deeper (shallower) thermocline (Figure S4 of the auxiliary material). Thus, a combination of the deeper (shallower) thermocline and weaker (stronger) upwelling in wCT (cCT) models prevents (facilitates) equatorial Pacific cooling, resulting in warmer (colder) SST in the equatorial Pacific cold tongue.

[15] Figure 3a shows the wCT-cCT composite difference in SST, surface wind and Do. Pronounced positive Do anomalies in the eastern equatorial basin and along the southeast coast of the Pacific indicate a reduced upwelling effect due ultimately to a deep thermocline in tropical oceans. On the equator, westerly wind anomalies in the western half of the basin are a response to and act to amplify the eastern SST warming by flattening the thermocline. This relationship between SST, zonal wind and Do is suggestive of Bjerknes feedback. Since the AMIP runs are forced with the observed
SST, CMIP minus AMIP difference represents the effect of SST bias and atmosphere-ocean interaction processes. Indeed, most of wind biases are due to the CMIP minus AMIP difference (Figure $3 \mathrm{~b}$ ), confirming the interaction with SST along the equator. Although weaker in magnitude, a similar relationship is found over the equatorial Atlantic among Do, SST and zonal wind. Thus, the equatorial cold tongue biases as represented by EOF2 are likely of oceanic origin: a deep thermocline causes a warm bias in the equatorial upwelling zone, which grows by inducing westerly wind anomalies via Bjerknes feedback.

\section{Summary and Discussion}

[16] We have examined the offset errors of tropical SST in CMIP multi-model ensembles by using the inter-model EOF analysis. The results suggest two types of tropical-wide offset biases: one reflects the tropical mean SST differences from observations and among models, with a broad meridional structure and of the same sign across all basins of up to $2{ }^{\circ} \mathrm{C}$ in magnitude; and one is linked to inter-model variability in the cold tongue temperatures in the equatorial Pacific and Atlantic. The first-type offset error is ascribed to atmospheric model representation of cloud cover, with cloudy models biasing low in tropical-wide SST, and the second type originates from the diversity among models in representing the thermocline depth, with deep thermocline models biasing warm in the equatorial cold tongues.

[17] SST biases affect precipitation over tropical oceans. Figure 4 shows the wT-cT composite difference in precipitation and SST. wT models feature more (less) rainfall in the equatorial (subtropical) oceans than cT models. The broad equatorial increase in precipitation in wT models is largely due to the CMIP-AMIP difference (Figures $4 c$ and $4 d$ ) and hence to the warm biases that peak at the equator. The CMIPAMIP rainfall difference follows the "warmer-get-wetter" 

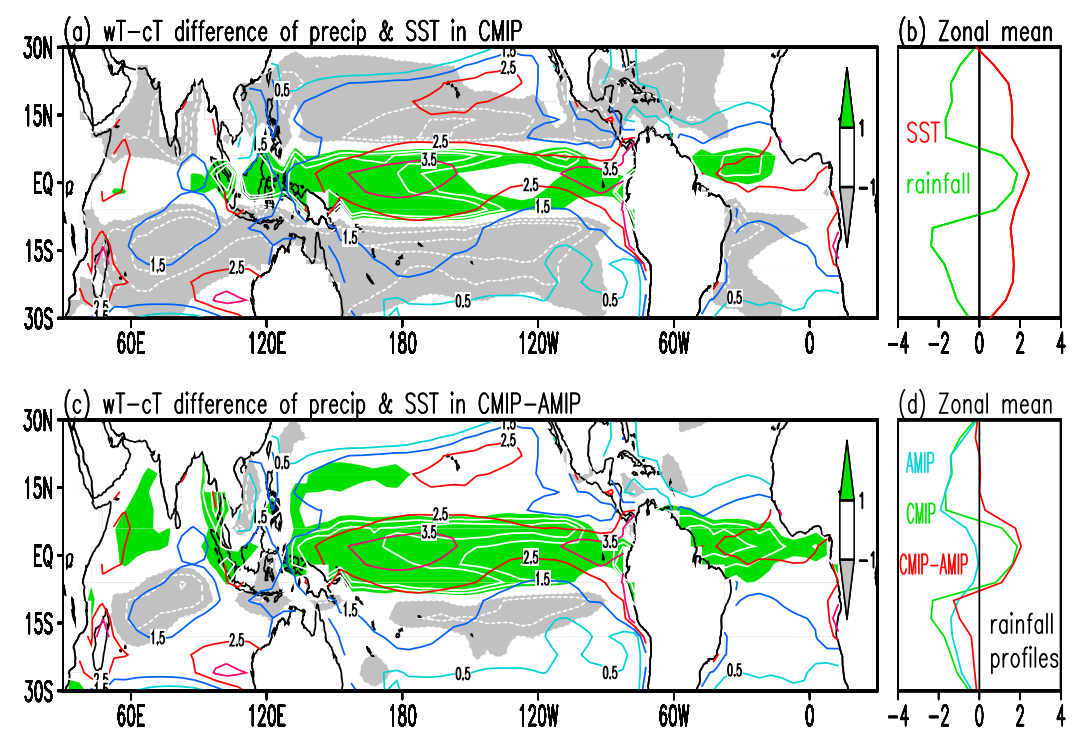

Figure 4. (a) Composite wT-cT difference of annual mean precipitation (green/gray shade and white contours at intervals of $1 \mathrm{~mm} /$ day) and SST (color contours, ${ }^{\circ} \mathrm{C}$; blue contours denote the tropical mean) in CMIP. (b) Zonal means of Figure 4a. (c, d) Same as in Figures 4a and 4b, but for CMIP-AMIP. Figures 4a-4d are calculated as M13 and M17 (high PC1 values) minus M4 and M12 (low PC1 values).

mechanism [Xie et al., 2010]; precipitation increases in regions where the SST warming exceeds the tropical mean, and vice versa. Indeed, the spatial correlation between intermodel anomalies of precipitation and SST deviation from the tropical mean SST is 0.52 within $20^{\circ} \mathrm{S}-20^{\circ} \mathrm{N}$. Johnson and Xie [2010] show that the tropical mean SST determines the SST threshold for convection over tropical oceans, because tropospheric temperature is flattened by equatorial waves and follows a moist-adiabatic profile set by the tropical mean SST. Thus, our results suggest that tropical-wide SST biases explain partly large inter-model diversity in precipitation climatology.

[18] A realistic climatology of the Pacific cold tongue is essential for the successful simulation of ENSO. Ham and Kug [2012] found that CGCMs with a cold SST bias in the Pacific cold tongue tend to simulate only a single type of El Nino, rather than the observed two, owing to the difficulty of these models to move convection to the eastern Pacific. Our finding that the cold tongue biases partly originate from the tropical wide biases in the thermocline depth will help reduce cold tongue errors and improve ENSO simulations and predictions.

[19] Acknowledgments. This research was supported by the National Basic Research Program of China (2012CB955600), NSF (ATM-0854365), NOAA and NASA. IPRC/SOEST publication \#929/8783.

[20] The editor thanks the two anonymous reviewers.

\section{References}

Bony, S., and J. L. Dufresne (2005), Marine boundary layer clouds at the heart of tropical cloud feedback uncertainties in climate models, Geophys. Res. Lett., 32, L20806, doi:10.1029/2005GL023851.

Cai, W., A. Sullivan, T. Cowan, J. Ribbe, and G. Shi (2011), Simulation of the Indian Ocean Dipole: A relevant criterion for selecting models for climate projections, Geophys. Res. Lett., 38, L03704, doi:10.1029/2010GL046242.

Chang, P., et al. (2006), Climate fluctuations of tropical coupled system: The role of ocean dynamics, J. Clim., 19, 5122-5174, doi:10.1175/JCLI3903.1.
Davey, M. K., et al. (2002), STOIC: A study of coupled model climatology and variability in tropical ocean regions, Clim. Dyn., 18, 403-420, doi:10.1007/s00382-001-0188-6.

de Szoeke, S. P., and S. P. Xie (2008), The tropical eastern Pacific seasonal cycle: Assessment of errors and mechanisms in IPCC AR4 coupled ocean-atmosphere general circulation models, J. Clim., 21, 2573-2590, doi:10.1175/2007JCLI1975.1.

Ham, Y. G., and J. S. Kug (2012), How well do current climate models simulate two types of El Nino?, Clim. Dyn., 39, 383-398, doi:10.1007/s00382-011$1157-3$.

Johnson, N. C., and S. P. Xie (2010), Changes in the sea surface temperature threshold for tropical convection, Nat. Geosci., 3, 842-845, doi:10.1038/ ngeo1008.

Lin, J. L. (2007), The double-ITCZ problem in IPCC AR4 coupled GCMs: Ocean-atmosphere feedback analysis, J. Clim., 20, 4497-4525, doi:10.1175/ JCLI4272.1.

Mechoso, C. R., et al. (1995), The seasonal cycle over the tropical Pacific in coupled ocean-atmosphere general circulation model, Mon. Weather Rev., 123, 2825-2838, doi:10.1175/1520-0493(1995)123<2825:TSCOTT $>2.0$. $\mathrm{CO} ; 2$.

Meehl, G. A., C. Covey, K. E. Taylor, T. Delworth, R. J. Stouffer, M. Latif, B. McAvaney, and J. F. Mitchell (2007), The WCRP CMIP3 multimodel dataset: A new era in climate change research, Bull. Am. Meteorol. Soc., 88, 1383-1394, doi:10.1175/BAMS-88-9-1383.

Richter, I., and S. P. Xie (2008), On the origin of equatorial Atlantic biases in coupled general circulation models, Clim. Dyn., 31, 587-598, doi:10.1007/ s00382-008-0364-z.

Saji, N. H., S. P. Xie, and T. Yamagata (2006), Tropical Indian Ocean variability in the IPCC twentieth century climate simulations, J. Clim., 19, 4397-4417, doi:10.1175/JCLI3847.1.

Sobel, A. H., I. M. Held, and C. S. Bretherton (2002), The ENSO signal in tropical tropospheric temperature, J. Clim., 15, 2702-2706, doi:10.1175/ 1520-0442(2002)015<2702:TESITT >2.0.CO;2.

Taylor, K. E., J. S. Ronald, and G. A. Meehl (2012), An overview of CMIP5 and the experiment design, Bull. Am. Meteorol. Soc., 93, 485-498, doi:10.1175/BAMS-D-11-00094.1.

Wang, C., and J. Picaut (2004), Understanding ENSO physics-A review, in Earth's Climate: The Ocean-Atmosphere Interaction, Geophys. Monogr. Ser, vol. 147, edited by C. Wang, S. P. Xie, and J. A. Carton, pp. 21-48, AGU, Washington, D. C., doi:10.1029/147GM02.

Xie, S. P., C. Deser, G. A. Vecchi, J. Ma, H. Teng, and A. T. Wittenberg (2010), Global warming pattern formation: Sea surface temperature and rainfall, J. Clim., 23, 966-986, doi:10.1175/2009JCLI3329.1. 